\title{
ANALISIS SWOT PENELITIAN DAN PENGABDIAN MASYARAKAT PUSAT PENGEMBANGAN KEWIRAUSAHAAN
}

\author{
Susantiningrum ${ }^{1,3}$ Eddy Triharyanto ${ }^{2,3}$, Dimar Hantari ${ }^{3}$ \\ ${ }^{1}$ Fakultas Keguruan dan Ilmu Pendidikan Universitas Sebelas Maret, Jl. Ir. Sutami No.36A, \\ Surakarta, 57126, Indonesia \\ ${ }^{2}$ Fakultas Pertanian Universitas Sebelas Maret, Jl. Ir. Sutami No.36A, Surakarta, 57126, \\ Indonesia \\ 3Pusat Pengembangan Kewirausahaan LPPM Universitas Sebelas Maret, Jl. Ir. Sutami No.36A, \\ Surakarta, 57126, Indonesia \\ Email: susantiningrum@staff.uns.ac.id
}

\begin{abstract}
ABSTRAK
Pusat Pengembangan Kewirausahaan (PPKwu) berupaya menjadi pusat mandiri yaitu pusat yang memiliki kegiatan unggulan yang berdampak pada peningkatan group index melalui penelitian dan pengabdian masyarakat (P2M). Penelitian ini bertujuan untuk meningkatkan kualitas dan kuantitas P2M sehingga diharapkan PPKwu dapat menjadi pusat studi yang mandiri dan unggul. Melalui penyusunan analisis SWOT ini diharapkan dapat meningkatkan dan menyinambungkan pelayanan pusat studi kepada mahasiswa dan masyarakat, serta meningkatkan Group Index sehingga dapat mencapai misi UNS yaitu UNS menuju world class university. Kegiatan penyusunan analisis SWOT dilakukan dengan metode Focus Group Discussion (FGD). Narasumber dan pembahas merupakan peergroup PPKwu. Hasil dari penelitian ini adalah didapatkannya analisis SWOT dan rencana perbaikan dari analisis SWOT tersebut. Adapun rencana perbaikan yang telah disusun antara lain: mengembangkan jaringan dan kerjasama untuk pengembangan kewirausahaan dengan berbagai pihak baik di dalam negeri maupun diluar negeri terkait penelitian dan pengabdian kepada masyarakat; meningkatkan kualitas layanan pengabdian berupa pendidikan \& pelatihan, konsultasi, pemagangan, pendampingan dan riset dibidang kewirausahaan; menginisiasi tumbuhnya WUB dikalangan mahasiswa dan masyarakat; melakukan riset terkait Pengembangan WUB dan usaha yang telah dimiliki oleh mahasiswa dan masyarakat; mempublikasikan hasil penelitian tentang pengembangan kewirausahaan melalui jurnal nasional maupun internasional serta website; membuat buku ajar tentang kewirausahaan dan budaya kewirausahaan; melakukan riset model pengembangan kewirausahaan; pengabdian fasilitasi WUB dan UMKM untuk mengajukan HKI.
\end{abstract}

Katakunci: analisis, ppkwu, pusat studi, SWOT 


\begin{abstract}
Pusat Pengembangan Kewirausahaan (PPKwu) seeks to become an independent study center, a center that has excellent activities that impact on increasing the group index through research and community service (P2M). This study aims to improve the quality and quantity of P2M so that it is expected to become an independent and superior study center. Through the preparation of a SWOT analysis, the study center is expected to improve and connect the study center services to students and the community, increase the Group Index so that it can achieve UNS's mission, UNS to become a world-class university. The preparation of SWOT analysis was carried out using the Focus Group Discussion (FGD) method. The resource persons and discussants are PPKwu peer groups. The results of this study are to obtain a SWOT analysis and a plan for improvement from the SWOT analysis. The improvement plans that have been prepared include: developing networks and cooperation for entrepreneurship development with various parties both domestically and abroad in relation to research and community service; improve the quality of Community Service in the form of education $\mathcal{E}$ training, consultation, apprenticeship, mentoring and research in the field of entrepreneurship; initiating the growth of WUB among students and society; conduct research related to the development of WUB and businesses that are owned by students and the community; publishing research results on entrepreneurship development through national and international journals and websites; making textbooks on entrepreneurship and entrepreneurial culture; conduct research on entrepreneurship development models; dedication of WUB and UMKM facilitation to apply for HKI.
\end{abstract}

Keywords: analysis, ppkwu, study center, SWOT

\section{PENDAHULUAN}

Pusat

Pengembangan

Kewirausahaan (PPKwu) konsisten dalam pengembangan kewirausahaan dan bisnis. Hal ini sesuai dengan budaya kerja ACTIVE UNS yaitu Entrepreneurship. Visi PPKwu adalah menjadi pusat riset dan layanan yang profesional, unggul dan terdepan di bidang kewirausahaan dan pengembangan bisnis bagi warga kampus dan masyarakat. Adapun misinya yaitu: (1) mewujudkan riset kepakaran dalam bidang kewirausahaan dan pengembangan bisnis, (2) membudayakan dan mengimplementasikan nilai-nilai kewirausahaan dalam kehidupan warga kampus dan masyarakat, (3) menumbuhkan wirausaha-wirausaha baru dari kalangan terdidik dan masyarakat, (4) mengembangkan pelaku bisnis yang profesional, mandiri dan inovatif yang berwawasan iptek.

PPKwu didukung oleh peer group dosen di lingkungan UNS, pakar, profesional, praktisi bisnis, serta staff administrasi dalam menjalankan programnya. PPKwu bekerjasama dengan fakultas dan lembaga di lingkungan UNS, perguruan tinggi negeri dan swasta, pemerintah pusat seperti Kemendikbud, Kemenristek, Kemenparekraf/ Baparekraf, Kementerian Koperasi \& UKM, Bank Indonesia, BUMN, pemerintah daerah, LSM, perusahaan, UKM, dan kelompok masyarakat serta didukung dengan fasilitas yang memadai.

Saat ini PPKwu berupaya 
menjadi pusat unggul dan mandiri yaitu pusat yang memiliki kegiatan unggulan yang berdampak pada peningkatan Group Index. Dalam proses menuju pusat mandiri maka diperlukan perbaikan manajemen dalam hal penelitian dan pengabdian masyarakat yang dilakukan oleh peergroup.

Perbaikan tersebut dapat dilakukan dengan mulai menyusun analisis SWOT mengenai penelitian dan pengabdian masyarakat. Menurut Istiqomah \& Andriyanto, (2017); Rahmayati (2015), analisis SWOT merupakan bagian dari perencanaan untuk menentukan sesuatu termasuk atau dikategorikan sebagai kekuatan, kelemahan, peluang dan ancaman. Mengembangkan kekuatan dan dan memperbaiki kelemahan dapat memastikan suatu tujuan tercapai (Tamara, 2016).

Hasil analisis tersebut diharapkan dapat digunakan sebagai pedoman untuk meningkatkan kinerja penelitian dan pengabdian kepada masyarakat Penelitian ini bertujuan untuk meningkatkan kualitas dan kuantitas P2M sehingga diharapkan PPKwu dapat menjadi pusat studi yang mandiri dan unggul.

\section{METODE}

Kegiatan penelitian penyusunan analisis SWOT P2M ini dilakukan dengan metode Focus Group Discussion (FGD) dengan narasumber peergroup PPKwu. Data dianalisis secara deskriptif. Kegiatan FGD dilaksanakan pada tanggal 18 September $2020 \mathrm{di}$ Hotel UNS Inn. Langkah-langkah dalam menyusun analisis SWOT antara lain: a. Melakukan klasifikasi data, faktorfaktor yang menjadi kekuatan dan kelemahan sebagai faktor internal, peluang dan ancaman sebagai faktor eksternal.

b. Membandingkan antara faktor eksternal dengan faktor internal.

c. Menginterpretasikan dan mengembangkan hasil analisis (poin b) menjadi keputusan memilih strategi yang memungkinkan untuk dilaksanakan.

d. Menyusun rencana perbaikan dan atau peningkatan dari hasil analisis SWOT untuk Group Index.

\section{HASIL DAN PEMBAHASAN}

Berdasarkan hasil FGD yang telah dilakukan, didapatkan analisis sebagai berikut:

\subsection{Strength (Kekuatan)}

a. Dimilikinya SDM yang memadai (staf administrasi, peergroup, konsultan bisnis)

b. Etos kerja dan akuntabilitas staff administrasi yang mumpuni

c. Memiliki unit riset pengembangan kewirausahaan

d. Memiliki Jurnal Kewirausahaan dan Bisnis Terakreditasi Peringkat 3 (SINTA 3)

e. Memiliki Website

f. Memiliki model pengembangan budaya kewirausahaan di perguruan tinggi

g. Melakukan pengelolaan organisasi yang transparan dan akuntabel

h. Sebagai LI/PI UMKM (Lembaga Intermediasi / Pusat Intermediasi UMKM) yang tersertifikasi oleh $\mathrm{BPPT}$ 


\subsection{Weakness (Kelemahan)}

a. Komitmen peer group untuk P2M kewirausahaan masih bersifat temporer

b. Hanya memiliki satu tenaga administrasi yang tetap. Empat lainnya tidak tetap

c. Sarana prasarana perkantoran yang belum memadai

\subsection{Opportunity (Peluang)}

a. Terbukanya jaringan kemitraan dan kerjasama dengan Lembaga di dalam negeri (Pemerintah, UKM, BUMN, Lembaga Keuangan, Perusahaan Milik Swasta, Perguruan Tinggi) terkait Penelitian dan Pengabdian

b. Terbukanya jaringan kemitraan dan kerjasama dengan lembaga di luar negeri terkait Penelitian dan Pengabdian

c. Minat dan potensi menjadi WUB di kalangan mahasiswa dan masyarakat meningkat

d. Isu Nasional dalam pengembangan kewirausahaan

e. Inovasi teknologi di bidang kewirausahaan yang masih rendah dalam masyarakat

f. Manajemen UMKM yang belum memenuhi standar

g. Jaringan pasar dan jaringan permodalan yang masih kurang

\subsection{Threat (Ancaman)}

a. Mental mahasiswa yang masih berorientasi kerja sebagai pegawai negeri sipil, bekerja di BUMN maupun di perusahaan swasta

b. Budaya masyarakat yang masih menempatkan bidang wirausaha sebagai pilihan terakhir c. Munculnya institusi yang bergerak dibidang yang sama dengan PPKwu

PPKwu memiliki SDM berupa staff administrasi berjumlah 5 orang. 1 orang merupakan pegawai UNS dan 4 orang merupakan pegawai tidak tetap. PPKwu juga didukung oleh 20 orang peergroup yang berasal dari berbagai fakultas. SDM adalah aset utama bagi sebuah lembaga, dimana setiap manusia memiliki kemampuan, keahlian, dan kreativitas yang berbeda-beda (Miftahuddin et al., 2018). Etos kerja yang dimiliki staff sudah terbukti mumpuni. Hal tersebut dapat dilihat dari tercapainya targettarget pekerjaan. Komitmen dan etos kerja merupakan aspek yang berperan penting dalam sebuah organisasi atau lembaga, karena komutmen dapat mempengaruhi efektifitas dan efisiensi pekerjaan (Susiawan \& Muhid, 2015).

Dari total 20 orang peergroup, komitmen untuk mengembangkan penelitian dan pengabdian masyarakat melalui PPKwu dirasa masih kurang. Dibuktikan dengan hanya sebagian kecil peergroup yang mengajukan P2M melalui PPKwu. Serta jarangnya peergroup berkunjung ke kantor PPKwu.

Semakin meningkatnya jaringan kerjasama antara PPKwu dengan lembaga pemerintah dan non pemerintah menjadikan peluang untuk melakukan penelitian dan pengabdian masyarakat oleh peergroup. Tidak sedikit kerjasama yang dilakukan PPKwu merupakan bidang kewirausahaan. Kerjasama dilakukan dengan harapan untuk mendapatkan hasil yang inovatif (Bolleyer, 2009; Suhartanta, 2012). 
Tabel 1. Strategi SWOT

\section{STRATEGI S-O}

STRATEGI W-O

1. Membangun kemitraan dan kerjasama dengan instansi terkait (pemerintah, BUMN, Lembaga Keuangan, Perusahaan milik swasta, Perguruan Tinggi) dibidang

Kewirausahaan terkait Penelitian dan Pengabdian

2. Melakukan pengabdian berupa pelatihan, pemagangan kewirausahaan bagi WUB baik mahasiswa maupun masyarakat

3. Melakukan pengabdian berupa pendampingan kepada WUB dan UMKM bagi mahasiswa dan masyarakat

4. Membangun jaringan antara lembaga keuangan dengan WUB dikalangan mahasiswa, maupun masyarakat.

5. Melakukan riset bidang kewirausahaan

6. Mendorong partisipasi WUB untuk mempromosikan produknya melalui pameran di dalam negri dan di luar negri.

7. Mempublikasikan hasil kegiatan WUB maupun pengembangan UKM dalam Jurnal dan Website

8. Melengkapi sarana prasarana

\begin{tabular}{|c|c|}
\hline STRATEGI S-T & STRATEGI W-T \\
\hline $\begin{array}{l}\text { 1. Membangun budaya kewirausahaan } \\
\text { dikalangan mahasiswa dan } \\
\text { masyarakat melalui program } \\
\text { pelatihan, pemagangan dan } \\
\text { pendampingan kewirausahaan }\end{array}$ & $\begin{array}{l}\text { 1. Menjalin kerjasama dengan } \\
\text { institusi yang bergerak dibidang } \\
\text { yang sama dengan PPKwu }\end{array}$ \\
\hline 2. Membuat klasterisasi usaha & $\begin{array}{l}\text { 2. Penguatan kemampuan peer } \\
\text { group melalui pelatihan dan } \\
\text { pemagangan }\end{array}$ \\
\hline $\begin{array}{l}\text { 3. Melakukan publikasi hasil-hasil } \\
\text { penelitian pentingnya kewirausahaan } \\
\text { melalui media cetak maupun } \\
\text { elektronik }\end{array}$ & $\begin{array}{l}\text { 3. Penguatan kemampuan staf } \\
\text { administrasi melalui pelatihan } \\
\text { dan pemagangan }\end{array}$ \\
\hline
\end{tabular}


Analisis SWOT selanjutnya di bentuk strategi pemecahan masalah (Tabel 1). Berdasarkan analisis SWOT tersebut terdapat beberapa strategi yang perlu dilakukan PPKwu untuk meningkatkan penelitian dan pengabdian masyarakat. Salah satunya adalah dilakukannya capacity building untuk peergroup dan staff administrasi. Tujuan capacity building tersebut adalah untuk meningkatkan rasa kekeluargaan, kerjasama dan kepemilikan. Capacity building merupakan salah satu bentuk pengembangan SDM untuk membekali dan membentuk pegawai sesuai dengan yang diharapkan organisasi atau perusahaan (Hassan et al., 2013; Kusnawan, 2008).

Hasil analisis SWOT ini menjadi dasar PPKwu untuk menentukan langkah selanjutnya dalam rangka meningkatkan penelitian dan pengabdian masyarakat. Hasil analisis SWOT menentukan kualitas dan kuantitas posisi organisasi yang kemudian membentuk rekomendasi berupa pilihan strategi generik serta kebutuhan atau modifikasi sumber daya organisasi (Chandra, 2015; Nofrizal \& Soviyanti, 2018). Berdasarkan analisis SWOT dapat disimpulkan rencana perbaikannya:

1. Mengembangkan jaringan dan kerjasama untuk pengembangan kewirausahaan dengan berbagai pihak baik di dalam negeri maupun diluar negeri terkait penelitian dan pengabdian kepada masyarakat

2. Meningkatkan kualitas layanan Pengabdian berupa Pendidikan \& pelatihan, konsultasi, pemagangan, pendampingan dan riset dibidang kewirausahaan
3. Menginisiasi tumbuhnya WUB dikalangan mahasiswa dan masyarakat

4. Melakukan riset terkait Pengembangan WUB dan Usaha yang telah dimiliki oleh mahasiswa dan masyarakat.

5. Mempublikasikan hasil penelitian tentang pengembangan kewirausahaan melalui jurnal nasional maupun internasional serta Website.

6. Membuat buku ajar tentang kewirausahaan dan budaya kewirausahaan.

7. Melakukan riset Model pengembangan kewirausahaan.

8. Pengabdian fasilitasi WUB dan UMKM untuk mengajukan HKI

Riset dibidang kewirausahaan masih perlu banyak dikaji. Salah satu yang menjadi fokus PPKwu sejak tahun 2014 adalah riset mengenai budaya kewirausahaan saat pendidikan dasar, menengah dan tinggi (Triharyanto et al., 2016; Triharyanto et al., 2018). Selain terus dilakukannya riset dibidang kewirausahaan perlu pula untuk melakukan publikasi hasil riset pada jurnal maupun prosiding ilmiah. Publikasi penting selain untuk meningkatkan personal indeks juga ikut kontribusi dalam kemajuan ilmu pengetahuan. Publikasi merupakan salah satu cara dan sarana untuk menyampaikan informasi sehingga memberikan kontribusi positif keilmuan (Nugrohoadhi, 2017; Salam et al., 2017). 


\section{KESIMPULAN}

Dalam rangka meningkatkan penelitian dan pengabdian masyarakat di PPKwu maka perlu dilakukan mengembangkan jaringan dan kerjasama untuk pengembangan kewirausahaan dengan berbagai pihak baik di dalam negeri maupun diluar negeri terkait penelitian dan pengabdian kepada masyarakat; meningkatkan kualitas layanan Pengabdian berupa Pendidikan \& pelatihan, konsultasi, pemagangan, pendampingan dan riset dibidang kewirausahaan; menginisiasi tumbuhnya WUB dikalangan mahasiswa dan masyarakat; melakukan riset terkait Pengembangan WUB dan Usaha yang telah dimiliki oleh mahasiswa dan masyarakat; mempublikasikan hasil penelitian tentang pengembangan kewirausahaan melalui jurnal nasional maupun internasional serta website; membuat buku ajar tentang kewirausahaan dan budaya kewirausahaan; melakukan riset Model pengembangan kewirausahaan; pengabdian fasilitasi WUB dan UMKM untuk mengajukan HKI.

\section{DAFTAR PUSTAKA}

Bolleyer, N. (2009). Intergovernmental Cooperation. Intergovernmental Cooperation.

https:/ / doi.org/10.1093/acprof:o so/9780199570607.001.0001

Chandra, E. Y. (2015). Analisis SWOT terhadap Pengelolaan Unit Kegiatan Mahasiswa Manna Proxia Theater Universitas Pelita Harapan. Jurnal Tata Kelola Seni, 1(2),

1-15. https://doi.org/10.24821/jtks.v1i 2.1636

Hassan, Z., Gaffar, M. N. A., \& Mokhtar, M. (2013). Pengembangan Sumber Daya Manusia: Studi Kasus Universitas Negeri di Malaysia. Jurnal Pendidikan Karakter, 3(1), 28-37.

Istiqomah, I., \& Andriyanto, I. (2017). Analisis SWOT dalam Pengembangan Bisnis (Studi pada Sentra Jenang di Desa Kaliputu Kudus). BISNIS : Jurnal Bisnis Dan Manajemen Islam, 5(2), 363-382. https://doi.org/10.21043/bisnis. v5i2.3019

Kusnawan, A. (2008). Manajemen Pelaksanaan Pelatihan Dakwah. Jurnal Ilmu Dakwah, 4(12), 335-370.

Miftahuddin, Rahman, A., \& Setiawan, A. I. (2018). Strategi Pengembangan Sumber Daya Manusia dalam Meningkatkan Kinerja Karyawan. Jurnal Manajemen Dakwah, 3(2), 1-16. https:/ / doi.org/10.15575/Fakult as

Nofrizal, N., \& Soviyanti, E. (2018). Analisis Swot untuk Menentukan Posisi Strategis pada Universitas Lancang Kuning Pekanbaru. Human Falah, 5(1), 96-116. https://doi.org/10.22202/econo mica.2018.v7.i1.2637

Nugrohoadhi, A. (2017). Pemanfaatan Publikasi Ilmiah di Perguruan Tinggi. Pustakaloka, 9(2), 266-282. https://doi.org/10.21154/pustak aloka.v9i2.1087

Rahmayati, H. . (2015). Analisis SWOT dalam Menentukan Strategi Pemasaran Udang Beku. Jurnal 
Galung Tropika, 4(1), 60-67.

Salam, R., Akhyar, M., Tayeb, A. M., \& Niswaty, R. (2017). Peningkatan Kualitas Publikasi Ilmiah Mahasiswa dalam Menunjang Daya Saing Perguruan Tinggi. Jurnal Office, 3(1), 61-65. https://doi.org/10.26858/jo.v3i1. 3463

Suhartanta. (2012). Kerjasama Kemitraan sebagai Upaya Meningkatkan Relevansi Lulusan Pendidikan Kejuruan. Prosiding Seminar Nasional Pendidikan Teknik Mesin FT UNY, 190-196.

Susiawan, S., \& Muhid, A. (2015). Kepemimpinan

Transformasional, Kepuasan Kerja dan Komitmen Organisasi. Persona:Jurnal Psikologi Indonesia, 4(03), 304-313. https:// doi.org/10.30996/person a.v4i03.725

Tamara, A. (2016). Implementasi Analisis Swot Dalam Strategi Pemasaran Produk Mandiri Tabungan Bisnis. Jurnal Riset Bisnis Dan Manajemen, 4(3), 395406.

https:/ / media.neliti.com/media/ publications/128155-ID-

implementasi-analisis-swotdalam-strateg.pdf

Triharyanto, E., Susantiningrum, Susilowati, T., \& Sutrisno, J. (2018). Growing of new entrepreneurs at university (Case study in Sebelas Maret University). International Journal of Engineering Sciences, 10(4), 158165.

Triharyanto, E., Susantiningrum, \&
Sutrisno, J. (2016). University Role in Developing Entrepreneurial Culture. Proceeding The 2nd International Conference on Teacher Training and Education Sebelas Maret University, November, 727733. 